\title{
LETTER TO THE EDITOR Cardiac complications in relapsed and refractory multiple myeloma patients treated with carfilzomib
}

Blood Cancer Journal (2015) 5, e272; doi:10.1038/bcj.2014.93; published online 16 January 2015

Carfilzomib is a novel, highly selective, tetrapeptide epoxyketone proteasome inhibitor that irreversibly binds to the $\mathrm{N}$-terminal threonine-containing active sites of the $20 \mathrm{~S}$ proteasome, which is the proteolytic core particle within the 26S proteasome, as compared with bortezomib, which reversibly inhibits the $20 \mathrm{~S}$ proteasome. ${ }^{1}$ In vitro, carfilzomib has demonstrated antiproliferative and proapoptotic activities in solid and hematologic tumor cells. $^{2}$

In animals, carfilzomib inhibited proteasome activity in blood and tissue and delayed tumor growth in models of multiple myeloma, hematologic and solid tumors. ${ }^{1}$ Proteasome inhibition was maintained for $\geqslant 48 \mathrm{~h}$ following the first dose of carfilzomib in each week of dosing. ${ }^{1}$ In addition, carfilzomib administration resulted in the inhibition of the low-molecular mass polypeptide two and multicatalytic endopeptidase complex-like one subunit of the immunoproteasome ranging from 26 to $32 \%$ and 41 to $49 \%$, respectively, at a dose of $20 \mathrm{mg} / \mathrm{m}^{2}$ (ref. 3).

In patients, carfilzomib has demonstrated efficacy and tolerability as a single agent and in combination regimens in patients with relapsed and/or refractory multiple myeloma (MM) in phase 2 studies. $^{4-7}$ In 2012, based on these results, carfilzomib was approved in the United States for single-agent use in the treatment of patients with MM who have received at least two prior therapies, including bortezomib and an immunomodulatory agent, and have demonstrated disease progression on or within 60 days of the completion of the last therapy. ${ }^{8}$

Carfilzomib has the advantage of a favorable safety profilemost notably a low incidence of peripheral neuropathy, which is a common complication with bortezomib-based regimens. However, recent studies and case reports suggest that treatment with proteasome inhibitors may be associated with cardiac events. ${ }^{9-11}$ An increasing body of evidence supports the assertion that deficient proteasome activity has a crucial role in the impairment of cardiac function. This effect may be mediated by several mechanisms, the most important of which is putatively the accumulation of unfolded, damaged and undegraded proteins inside myocytes. ${ }^{11-13}$ However, limited data are currently available on cardiac adverse events associated with carfilzomib treatment.

Between 2009 and 2012, which was before regulatory approval of carfilzomib in the United States, we treated 130 patients with relapsed and/or refractory $\mathrm{MM}$, either on a phase 2 compassionate carfilzomib protocol $(n=118)$ or as single-patient treatment with an investigational new drug $(n=12)$. We herein report data on those patients who developed a significant cardiovascular adverse event, which was defined as hospitalization owing to a cardiac complication during the first two cycles of therapy with carfilzomib either alone or with dexamethasone. Patients with hospitalization attributed to other causalities, such as infections, or who received concomitant anti-MM drugs were excluded from this analysis. We also describe subsets of patients with baseline echocardiogram findings from before and during carfilzomib treatment and with brain natriuretic peptide (BNP) measurements gathered at baseline and during follow-up.
Patients were orally hydrated with $\sim 30 \mathrm{ml} / \mathrm{kg} /$ day of liquid ( 6 to 8 cups of liquid per day) starting $48 \mathrm{~h}$ before the first dose of carfilzomib. Patients were also given intravenous prehydration with $250 \mathrm{ml}$ of normal saline. Carfilzomib was then coadministered with dexamethasone; dexamethasone was typically given at a dose of $4 \mathrm{mg}$, but dose escalation was allowed. The addition of other anti-MM agents was permitted after cycle 1 in absence of at least partial response per International Myeloma Working Group criteria. Descriptive statistics were performed on the study cohort and clinical and echocardiographic results. Levels of BNP were evaluated as markers for myocardiac dysfunction or excessive stretching of cardiomyocytes. To compare BNP values from before and during treatment, we used a Wilcoxon signed-rank test with continuity correction, using the software R, v2.15.1. ${ }^{14}$ All patients had creatinine levels $<3.0 \mathrm{mg} / \mathrm{dl}$ before treatment.

Within our cohort study, we identified 26 patients out of the total 130 patients who met the previously discussed criteria for significant cardiac adverse events (Table 1; Supplementary Table 1). The population was composed of $58 \%$ males and $42 \%$ females, and the median age was 65 years (range, $47-86$ years). The median number of previous lines of treatment was 6 (range, 1-24). Patients had a median of 1 transplantation (range, 1-4 transplantations). Patients received a median of two cycles of carfilzomib (range, 1-24 cycles) and a median dose of $36 \mathrm{mg} / \mathrm{m}^{2}$ carfilzomib (range, $20-45 \mathrm{mg} / \mathrm{m}^{2}$ ). The median total previous lifetime dose of doxorubicin was $120 \mathrm{mg} / \mathrm{m}^{2}$ (range, $40-280 \mathrm{mg} / \mathrm{m}^{2}$ ). More than half of the identified patients $(n=14 ; 54 \%)$ had a history of cardiac events, including hypertension $(n=7)$, atrial fibrillation $(n=5)$, supraventricular tachycardia $(n=4)$ and congestive heart failure $(n=3)$.

Although receiving treatment with carfilzomib, 11 patients were hospitalized for congestive heart failure alone and 4 patients were admitted for congestive heart failure with hypotension (Supplementary Table 1). Five patients were admitted for hypotension alone. Hypotension was also reported with arrhythmia in three patients. Pulmonary edema led to the hospitalization of two patients and included one case of severe hypertensive crisis. Arrhythmia alone resulted in hospitalization for one patient. Among the 12 patients who were hospitalized for hypotension, 7 had severely low blood pressure. Among the four patients who were hospitalized for arrhythmia, two had cardiac arrest due to arrhythmias.

The initial carfilzomib clinical trials ${ }^{4-6}$ were designed with carfilzomib administered as a 2-10 min infusion, based on preclinical pharmacokinetic and pharmacodynamic data. The recently reported FOCUS trial demonstrated a cardiac event rate of $\sim 4.5 \%$ with the carfilzomib $20 / 27 \mathrm{mg} / \mathrm{m}^{2}$ schedule, ${ }^{15}$ which is consistent with data reported in the carfilzomib registration phase 2 study. ${ }^{8}$ Between 2009 and 2010, we observed an increased incidence of cardiac events, leading us to arbitrarily change the infusion time for all carfilzomib dosing levels to $30 \mathrm{~min}$. Interestingly, 20 of the 26 cases of serious cardiac events reported here occurred in patients receiving the 2-10 min infusion and included 15 patients being treated at doses higher than the $27 \mathrm{mg} / \mathrm{m}^{2}$.

Owing to concerns regarding cardiopulmonary adverse events, we also performed echocardiograms at baseline and as 


\begin{tabular}{|c|c|c|c|c|c|}
\hline Patient & $\begin{array}{l}\text { Doxorubicin } \\
\text { dose, } m g\end{array}$ & Transplants, $\mathrm{n}$ & CFZ cycles, $\mathrm{n}$ & $\begin{array}{c}\text { Maximum CFZ dose, } \\
\mathrm{mg} / \mathrm{m}^{2}\end{array}$ & Cardiac history \\
\hline 1 & 120 & 4 & 1 & 20 & None \\
\hline 2 & 200 & 2 & 14 & 36 & HTN \\
\hline 3 & 160 & 0 & 1 & 27 & SVT, HTN \\
\hline 4 & 80 & 0 & 1 & 27 & None \\
\hline 5 & 200 & 3 & 1 & 27 & None \\
\hline 6 & 160 & 2 & 1 & 20 & None \\
\hline 7 & 280 & 3 & 3 & 36 & None \\
\hline 8 & 80 & 0 & 3 & 27 & Atrial fibrillation, SVT, mitral regurgitations \\
\hline 9 & 40 & 2 & 1 & 27 & Atrial fibrillation \\
\hline 10 & 80 & 2 & 2 & 36 & CAD, bradycardia \\
\hline 11 & 40 & 1 & 12 & 36 & $\mathrm{CHF}$ \\
\hline 12 & 120 & 2 & 1 & 45 & None \\
\hline 13 & 40 & 1 & 24 & 45 & HTN \\
\hline 14 & 40 & 0 & 2 & 36 & None \\
\hline 15 & 280 & 3 & 2 & 45 & LVH \\
\hline 16 & 200 & 1 & 2 & 36 & Atrial fibrillation \\
\hline 17 & 240 & 2 & 2 & 36 & None \\
\hline 18 & 120 & 0 & 1 & 27 & CHF, HTN \\
\hline 19 & 160 & 3 & 1 & 20 & None \\
\hline 20 & 120 & 0 & 3 & 45 & None \\
\hline 21 & 280 & 4 & 5 & 36 & None \\
\hline 22 & 80 & 1 & 3 & 36 & $\mathrm{CHF}, \mathrm{SVT}$, atrial fibrillation \\
\hline 23 & 80 & 1 & 1 & 36 & Atrial fibrillation, HTN \\
\hline 24 & - & 1 & 3 & 27 & None \\
\hline 25 & 120 & 1 & 6 & 45 & HTN, SVT \\
\hline 26 & 80 & 1 & 2 & 27 & HTN \\
\hline
\end{tabular}

Abbreviations: CAD, coronary artery disease; CFZ, carfilzomib; CHF, congestive heart failure; HTN, hypertension; LVH, left ventricular hypertrophy; SVT, supraventricular tachycardia.

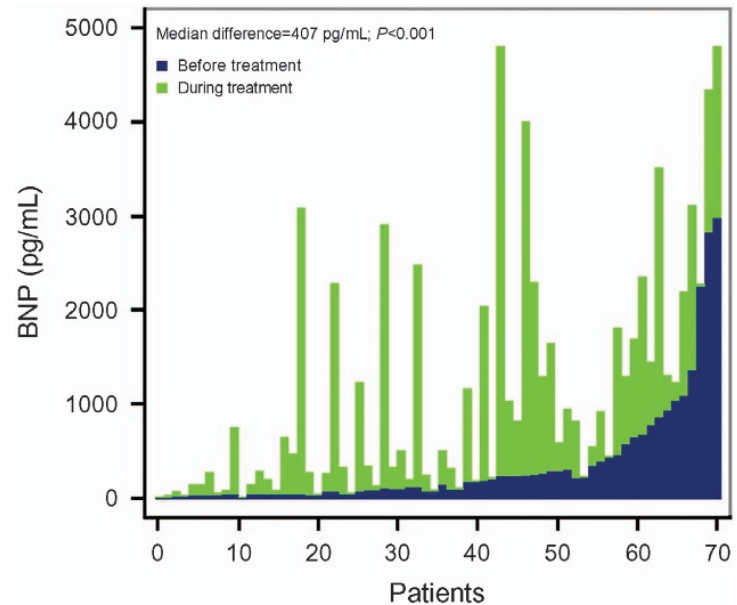

Figure 1. BNP levels. BNP levels were compared before and during treatment with carfilzomib. BNP, brain natriuretic peptide.

symptom-driven follow-ups $(n=93)$. Among these patients, the median ejection fraction as assessed by echocardiogram dropped from 55 to $33 \%$. Sixty-nine of 130 patients also had baseline BNP measurements and measurements during the first cycle of carfilzomib. Among these patients, a median increase of $407 \mathrm{pg} / \mathrm{ml}$ BNP from baseline was observed $(P<0.001$; Figure 1). Elevation of BNP did not appear to correlate with clinical symptoms or hospitalization.

In conclusion, this retrospective, single-center study observed that among patients receiving carfilzomib, a number experienced increased BNP levels, cardiac events confirmed by echocardiogram and/or serious cardiovascular events that required hospitalization. Proteasome inhibition has been shown to impair cardiac function, as evidenced in murine models and clinical studies of bortezomib ${ }^{9-11}$; this, however, is the first clinical study of cardiac dysfunction following carfilzomib treatment. The SWOG 1304 phase 2 study, which compares standard-dose $\left(20 / 27 \mathrm{mg} / \mathrm{m}^{2}\right)$ with high-dose $\left(20 / 56 \mathrm{mg} / \mathrm{m}^{2}\right)$ carfilzomib, included serial cardiac profiling in its study design to better examine any cardiac events (https://clinicaltrials.gov/ct2/show/NCT01903811); similar end points are included in the ENDEAVOR phase 3 trial that compares carfilzomib-dexamethasone with bortezomib-dexamethasone (http://clinicaltrials.gov/show/NCT01568866).

Most patients in our study who reported a serious cardiovascular event also had a history of cardiac events and exposure to doxorubicin. The authors advise that caution should be exercised when using carfilzomib in patients with cardiac comorbidities and prior therapy with cardiotoxic agents. Increasing the infusion time to 30 min across all dosing levels may lead to a decrease in the occurrence of cardiac events, as we observed in our single-center experience.

\section{CONFLICT OF INTEREST}

SZU is a consultant to Celgene, Millennium, Onyx and Sanofi. He has received research funding from ArrayBioPharma, Celgene, Onyx, Janssen and Pharmacyclics and speaking honoraria from Celgene, Millennium and Onyx. BB has received research funding from Celgene and Novartis. He is a consultant to Celgene and Genzyme and has received speaking honoraria from Celgene and Millennium. BB is a coinventor on patents and patent applications related to use of gene expression profiling in cancer medicine. The remaining authors declare no conflict of interest.

\section{ACKNOWLEDGEMENTS}

Editorial assistance was provided by BlueMomentum, a division of KnowledgePoint360, an Ashfield Company, and supported by Onyx Pharmaceuticals, Inc., an Amgen subsidiary. 
S Atrash ${ }^{1}$, A Tullos ${ }^{1}$, S Panozzo ${ }^{1}$, M Bhutani ${ }^{2}$, F Van Rhee ${ }^{1}$ B Barlogie ${ }^{1}$ and SZ Usmani ${ }^{2}$

${ }^{1}$ Myeloma Institute for Research and Therapy, University of Arkansas for Medical Sciences, Little Rock, AR, USA and ${ }^{2}$ Levine Cancer Institute, Carolinas HealthCare System,

Charlotte, NC, USA

E-mail: saad.usmani@carolinashealthcare.org

\section{REFERENCES}

1 Demo SD, Kirk CJ, Aujay MA, Buchholz TJ, Dajee M, Ho MN et al. Antitumor activity of PR-171, a novel irreversible inhibitor of the proteasome. Cancer Res 2007; 67: 6383-6391.

2 Yang J, Wang $Z$, Fang $Y$, Jiang J, Zhao F, Wong $\mathrm{H}$ et al. Pharmacokinetics, pharmacodynamics, metabolism, distribution, and excretion of carfilzomib in rats. Drug Metab Dispos 2011; 39: 1873-1882.

3 Parlati F, Lee SJ, Aujay M, Suzuki E, Levitsky K, Lorens JB et al. Carfilzomib can induce tumor cell death through selective inhibition of the chymotrypsin-like activity of the proteasome. Blood 2009; 114: 3439-3447.

4 Siegel DS, Martin T, Wang M, Vij R, Jakubowiak AJ, Lonial S et al. A phase 2 study of single-agent carfilzomib (PX-171-003-A1) in patients with relapsed and refractory multiple myeloma. Blood 2012; 120: 2817-2825.

5 Vij R, Wang M, Kaufman JL, Lonial S, Jakubowiak AJ, Stewart AK et al. An open-label, single-arm, phase 2 (PX-171-004) study of single-agent carfilzomib in bortezomib-naive patients with relapsed and/or refractory multiple myeloma. Blood 2012; 119: 5661-5670.

6 Wang M, Martin T, Bensinger W, Alsina M, Siegel DS, Kavalerchik E et al. Phase 2 doseexpansion study (PX-171-006) of carfilzomib, lenalidomide, and low-dose dexamethasone in relapsed or progressive multiple myeloma. Blood 2013; 122: 3122-3128.

7 Siegel D, Martin T, Nooka A, Harvey RD, Vij R, Niesvizky R et al. Integrated safety profile of single-agent carfilzomib: experience from 526 patients enrolled in 4 phase II clinical studies. Haematologica 2013; 98: 1753-1761.
8 Kyprolis [prescribing information]. South San Francisco; CA: Onyx Pharmaceuticals Inc, 2012.

9 Papandreou CN, Daliani DD, Nix D, Yang H, Madden T, Wang X et al. Phase I trial of the proteasome inhibitor bortezomib in patients with advanced solid tumors with observations in androgen-independent prostate cancer. J Clin Oncol 2004; 22: 2108-2121.

10 Honton B, Despas F, Dumonteil N, Rouvellat C, Roussel M, Carrie D et al. Bortezomib and heart failure: case-report and review of the French Pharmacovigilance database. Fundam Clin Pharmacol 2014; 28: 349-352.

11 Enrico O, Gabriele B, Nadia C, Sara G, Daniele V, Giulia C et al. Unexpected cardiotoxicity in haematological bortezomib treated patients. Br J Haematol 2007; 138: $396-397$

12 Willis MS, Patterson C. Into the heart: the emerging role of the ubiquitinproteasome system. J Mol Cell Cardiol 2006; 41: 567-579.

$13 \mathrm{Li} \mathrm{YF}$, Wang X. The role of the proteasome in heart disease. Biochim Biophys Acta 2011; 1809: 141-149.

$14 \mathrm{R}$ Core Team. R: A Language and Environment for Statistical Computing. R Foundation for Statistical Computing: Baltimore, MD, USA, 2013. Available at http://www.r-project.org/.

15 Ludwig $\mathrm{H}$, Masszi T, Petrucci MT, Palumbo A, Rosiñol L, Nagler A et al. Carfilzomib (K) vs low-dose corticosteroids and optional cyclophosphamide (CY) in patients (pts) with relapsed and refractory multiple myeloma (RRMM): results from a phase 3 study (FOCUS). Ann Oncol 2014; 25(Suppl 5): v1 (abstract LBA28).

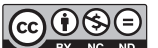

This work is licensed under a Creative Commons AttributionNonCommercial-NoDerivs 4.0 International License. The images or other third party material in this article are included in the article's Creative Commons license, unless indicated otherwise in the credit line; if the material is not included under the Creative Commons license, users will need to obtain permission from the license holder to reproduce the material. To view a copy of this license, visit http:// creativecommons.org/licenses/by-nc-nd/4.0/

Supplementary Information accompanies this paper on Blood Cancer Journal website (http://www.nature.com/bcj) 